[Technical Paper]

\title{
Novel Thin Copper Transfer Films for Fine Line Formation on PCB Substrates
}

\author{
Hirohisa Narahashi*, Shigeo Nakamura*, and Tadahiko Yokota** \\ *Product Development Dept. Aminoscience Laboratories, Amino Acids Company, Ajinomoto Co., Inc,. 1-1. Suzuki-cho, Kawasaki-ku, Kawasaki-shi \\ 210-8681, Japan \\ **Electronic Materials Division, Ajinomoto Fine-Techno Co., Inc., 1-2. Suzuki-cho, Kawasaki-ku, Kawasaki-shi 210-0801, Japan
}

(Received August 12, 2010; accepted October 31, 2010)

\begin{abstract}
Printed circuit boards (PCB) using Ajinomoto build-up films (ABF) as insulating layers are widely used as package substrates. Along with the increasing demand for downsizing electronic devices with advanced functions, package substrates are strongly required to be miniaturized with high-density circuit wirings.

The manufacturing method for multilayer PCBs using ABF is a semi-additive process including the lamination and curing steps of $\mathrm{ABF}$ resin composition, laser via formation and then desmear process accompanied with roughening the $\mathrm{ABF}$ surface prior to electroless copper plating as a seed layer to electroplate a thicker copper layer. The high adhesion between the plated copper and $\mathrm{ABF}$ insulating layer depends mainly on an anchor effect; however a smooth surface is desired for fine line formation, for example, of less than $\mathrm{L} / \mathrm{S}=15 / 15$ microns.

Recently, we've developed very thin copper transfer films consisting of a supporter film, an alkaline-soluble resin layer, and a thin copper layer (150-1500 nm thick) deposited by vacuum evaporation or sputtering. In this paper, we report on the applications of very thin copper transfer films for both build-up PCB and core materials. With regard to build-up applications, the combination of a new ABF that has a low coefficient of thermal expansion and a high Young's modulus is demonstrated as a high-tech resin coated copper (RCC) film for fine line formation. Furthermore, the combination of very thin copper transfer film and ABF-prepregs, which are glass-cloth materials impregnated with $\mathrm{ABF}$ resin compositions, are proposed for use as core materials, especially for CSP substrates.

These new applications can achieve the high adhesion between the copper and insulating layers without anchor effects and that mechanism is presumed from the analysis of its interface using XPS. In addition, reliability tests were performed under the stress conditions of reflow tests and HAST.
\end{abstract}

Keywords: Printed Circuit Board (PCB), Low Surface Roughness, High Adhesion Strength, Dielectric Material, Build-up Material

\section{Introduction}

Printed circuits boards (PCBs) such as multi-layer printed wiring boards and flexible printed wiring boards are used for a wide variety of electronic devices. Along with an increasing demand for downsizing highperformance electronic devices, there is pressure for substrates for packages installed with semiconductors in such devices to be miniaturized with high-density circuit wirings.[1]

PCBs using Ajinomoto build-up films (ABF) [2] as insulating layers are widely used for package substrates. The manufacturing process for multilayer $\mathrm{PCBs}$ using $\mathrm{ABF}$ is a semi-additive process (SAP) including the lamination and curing of the ABF resin composition, the formation of laser vias, and a desmear process using an alkaline permanganate solution to form micro anchors on the $\mathrm{ABF}$ surface prior to electroless copper plating as a seed layer for thicker electrolytic copper plating.

This process provides the high adhesion strength (peel strength) between the insulating layer and the plated copper by roughening the surface of the insulating layer. However, this anchor effect prevents the very fine line forma- 
tion of less than $\mathrm{L} / \mathrm{S}=15 / 15 \mu \mathrm{m}$ because the relatively long time required to remove the seed layer of the anchor parts at the flash etching step (differential etching) of the SAP noticeably dissolves the copper lines. Therefore, both a dielectric material and a manufacturing process that can produce high adhesion strength with a smooth interface between an insulating layer and a conductive layer are strongly desired for future fine line formation.

Hence, we have investigated the adhesion phenomena and mechanism between various dielectric materials and a smooth copper surface, and found the specific phenomenon of ABF-GX13 that produced high adhesion with smooth pure copper deposited by sputtering or vacuum evaporation. In order to provide the smooth pure copper on the $\mathrm{ABF}$ resin surface, we first developed a thin copper transfer film consisting of a support film, an alkalinesoluble resin layer and a thin copper layer deposited by vacuum evaporation or sputtering. The alkaline-soluble resin layer allows the uniform copper transfer by releasing the interface between the support film and its resin layer after curing with ABF. Furthermore, we combined the thin copper transfer film with a new ABF which has a low coefficient of thermal expansion, a high Young's modulus and a low dielectric loss tangent, which we call a special resin coated copper (RCC), as a build-up material for fine line formation. In addition, the core material, a copper-clad laminate (CCL), AGL-1020, which consists of glass-cloth materials impregnated with $\mathrm{ABF}$ resin compositions and thin copper transfer films was developed similarly, and can provide very fine line formation with core boards.

In this paper, we report on the special ABF-RCC and CCL using thin copper transfer films, focusing not only on their properties but also on the processes using these materials.

\section{Build-up Material, RCC Consisting of New ABF and Thin Copper Transfer Film}

\subsection{Construction}

Figure 1 shows the construction of the ABF-RCC. The thin copper transfer film was made by the following steps: coating and drying the alkaline-soluble resin ( $1 \mu \mathrm{m}$ thick, release layer) on PET (38 $\mu \mathrm{m}$ thick), and depositing a 1 $\mu \mathrm{m}$ thick copper layer on the release layer by vacuum evaporation. Then, a thin copper transfer film was hotlaminated with the new $40 \mu \mathrm{m}$ thick ABF to get the RCC.

Table 1 shows the characteristics of the ABF-GX13 and new $\mathrm{ABF}$ after curing (the cure conditions for the ABFGX13: 180 degC for $90 \mathrm{~min}$; those for the new ABF; 190

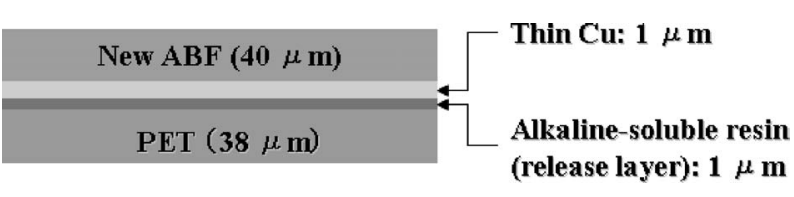

Fig. 1 Construction of ABF-RCC (cross section).

Table 1 General characteristics of ABF-GX13 and new ABF after curing.

\begin{tabular}{c|c|c|c}
\hline Test condition & Unit & GX-13 & New ABF \\
\hline $\begin{array}{c}\text { CTE x-y (25-150 degC) } \\
\text { (tensile TMA) }\end{array}$ & ppm/degC & 46 & 23 \\
\hline $\begin{array}{c}\text { CTE x-y (150-240 degC) } \\
\text { (tensile TMA) }\end{array}$ & ppm/degC & 120 & 78 \\
\hline Tg (tensile TMA) & $\operatorname{degC}$ & 156 & 154 \\
\hline Tg (DMA) & degC & 177 & 172 \\
\hline Young's modulus & GPa & 4.0 & 7.5 \\
\hline Tensile strength & $\mathrm{MPa}$ & 93 & 104 \\
\hline Elongation & $\%$ & 5.0 & 2.4 \\
\hline $\begin{array}{c}\text { Dielectric constant } \\
\text { (Cavity perturbation, 5.8 GHz) }\end{array}$ & - & 3.1 & 3.4 \\
\hline $\begin{array}{c}\text { Loss tangent } \\
\text { (Cavity perturbation, 5.8 GHz) }\end{array}$ & - & 0.019 & 0.014 \\
\hline $\begin{array}{c}\text { Water absorption } \\
\text { 100 degC, 1 h }\end{array}$ & $\mathrm{wt} \%$ & 1.1 & 0.6 \\
\hline \begin{tabular}{c} 
Flame retardancy (UL94) \\
\hline
\end{tabular} & - & $\doteqdot \mathrm{V} 0$ & $\doteqdot \mathrm{V} 0$ \\
\hline
\end{tabular}

$\operatorname{deg} \mathrm{C}$ for $90 \mathrm{~min}$ ). The new $\mathrm{ABF}$ is the latest development of the GX-series that has a low CTE, a high Young's modulus, and a low dielectric loss tangent in comparison with the conventional ABF-GX13 which is and a current commercial ABF.

\subsection{Manufacturing process availability using new} ABF-RCC

Figure 2 shows the typical manufacturing process using the new ABF-RCC. The process is similar to SAP, including lamination of the ABF-RCC to the core board with through holes (TH) and circuit patterns, curing of the new $\mathrm{ABF}$, removal of the PET film, laser drilling for via formation, dissolution of release layer, desmear for cleaning the via bottoms, electroless copper plating, and patterning.

Some processes using metal transfer films composed of supporter films and release layers have been tried for use in forming circuit wirings. [3] In these processes, the metal layer is transferred onto the resin composition after curing and release of the supporter film. The detachment of the supporter film occurs at the interface between the release layer and metal layer. However the release properties of the supporter films after curing are poor (release strength 
1. ABF-RCC cutting \& placement

5. Laser drilling

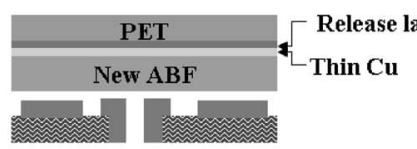

2. Lamination of ABF-RCC

3. Curing

$\left(100 \operatorname{deg} C^{*} 30 \mathrm{~min}+180 \operatorname{deg} C^{*} 30 \mathrm{~min}\right)$

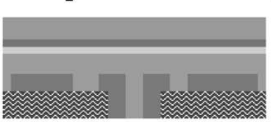

4. Removal of PET film

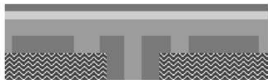

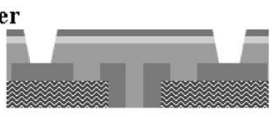

6. Dissolution of release layer 7. Desmear

8. Electroless copper plating
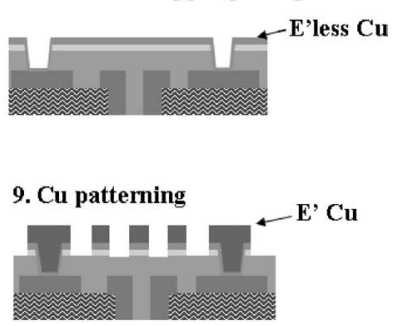

※ One side of the core is shown by space restrictions.

Fig. 2 Manufacturing process using ABF-RCC.

is high), and uniform transfer of metal layer onto the resin composition is difficult.

On the other hand, with the new ABF-RCC, the thin copper layer is transferred onto the resin composition after curing and detachment easily from the PET film at the interface between the PET film and release layer. After detachment of the PET film, the release layer remains on the thin copper layer. These features are key points for the uniform transfer of the thin copper layer.

Furthermore, during via formation by direct laser drilling, the release layer on the thin copper prevents residues generated during laser drilling from attaching to the thin copper layer used as seed layer.

\subsection{Lamination process availability}

First, the through-hole filling property was evaluated in order to check the resin fluidity of the new ABF. The preparation and method are as follows: A thin copper transfer film was prepared by coating an alkaline-soluble resin on PET film, drying at $130 \mathrm{deg}$ for $10 \mathrm{~min}$, and depositing a $1.0 \mu \mathrm{m}$ thick copper layer using a vacuum evaporator. Then, the thin copper transfer film was hot-laminated to the new $\mathrm{ABF}$ using a roll laminator to get the new $\mathrm{ABF}$ RCC. Next, the new ABF-RCC was cut and laminated to the core board using TH as shown in Figure 3. The lamination condition included reducing the pressure for $30 \mathrm{sec}$ and rubber pressing at $0.7 \mathrm{MPa}$ and $100 \mathrm{degC}$ for $30 \mathrm{sec}$, and further SUS-pressing at $0.54 \mathrm{MPa}$ and $100 \mathrm{degC}$ for 30 sec. Then, the new ABF was cured at $100 \mathrm{degC}$ for $30 \mathrm{~min}$ and $180 \mathrm{degC}$ for $30 \mathrm{~min}$. After that, the PET film, which is a supporter layer for the thin copper transfer film, was released and the resin layer (release layer) was removed using a $2 \% \mathrm{NaOH}$ aqueous solution at room temperature.
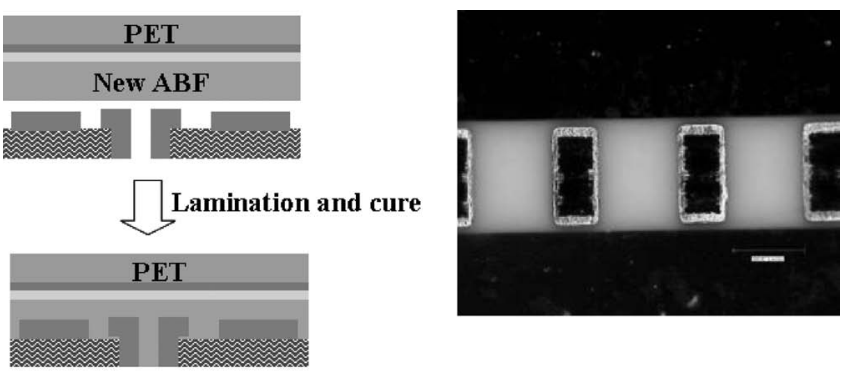

※ Core board : thickness $=0.3 \mathrm{mmt}$, ТНФ $300 \mu \mathrm{m}$ ※ Laminate condition:

$1^{\text {st }} .100$ deg.C, 30 s vac., 30 s rubber press, + $0.7 \mathrm{MPa}$ Air

$2^{\text {nd }} .100$ deg.C, $60 \mathrm{~s}$, SUS press, $0.54 \mathrm{MPa}$

※ure : 100 deg $\mathrm{C} * 30 \mathrm{~min} .+180$ degC $* 30 \mathrm{~min}$

Fig. 3 Process of ABF-RCC lamination and cross sectional photograph of $\mathrm{TH}$ after lamination and curing.

Thereafter, the cross-sectional TH was observed using a microscope after thin copper etching with an $\mathrm{FeCl}_{3}$ solution. ABF-RCC shows the good TH filling property without significant surface dents $(<2.0 \mu \mathrm{m})$, which means the same efficient lamination process as GX13 can be used.

\subsection{Adhesive strength and reliabilities}

The adhesion between the new $\mathrm{ABF}$ and copper was investigated using the following steps: After removal of the alkaline-soluble resin layer (release layer), the sample was prepared using the method described in Section 2.3. After that, a $0.3 \mu \mathrm{m}$ electroless copper plating layer was formed on the thin copper layer, and the sample was dried at 80 $\operatorname{deg} \mathrm{C}$ for $15 \mathrm{~min}$. Next, $25 \mu \mathrm{m}$ thick electrolytic copper plating was formed on the electroless copper plating layer. After electrolytic copper plating, the sample was annealed at $180 \mathrm{degC}$ for $30 \mathrm{~min}$. The annealed sample was used for the tests of adhesion strength and reliability. Adhesion strength (peel strength) was measured according to JIS6481. After measuring the initial peel strength, those samples were subjected to Highly Accelerated Stress Testing (HAST) or reflow tests after preconditioning to check the adhesive reliability. Preconditioning (JEDEC Level 2) was carried out at $85 \mathrm{degC} / 60 \% \mathrm{RH}$ for $168 \mathrm{~h}$. The HAST condition was $130 \mathrm{degC} / 85 \% \mathrm{RH}$ for $100 \mathrm{~h}$, and reflow was carried out five times with a peak temperature of $262 \mathrm{degC}$. Furthermore, the roughness of the interface between the new $\mathrm{ABF}$ and the thin copper layer was measured using WYKO (laser-interference type surface measurements) after the thin copper was etched out. These results are summarized in Table 2. High adhesion strength with a very smooth interface was obtained and maintained after HAST or reflow tests. 
Table 2 Results of peel strength for new $\mathrm{ABF}$

\begin{tabular}{c|c|c}
\hline Tests & Unit & Results \\
\hline $\begin{array}{c}\text { Peel strength } \\
\text { (initial) }\end{array}$ & $\mathrm{kgf} / \mathrm{cm}$ & 1.1 \\
\hline $\begin{array}{c}\text { Peel strength } \\
\text { (after HAST and precondition) }\end{array}$ & $\mathrm{kgf} / \mathrm{cm}$ & 0.8 \\
\hline $\begin{array}{c}\text { Reflow tests } \\
\text { (after HAST and precondition) }\end{array}$ & - & No blister \\
\hline Surface roughness & $\mathrm{nm}$ & $\begin{array}{c}\text { Ra: } 50 \\
\text { Rz: } 900\end{array}$ \\
\hline
\end{tabular}

※Precondition: JEDEC Level 2 (85 deg, 60\% RH, 168 h) ※Reflow max temp.: $262 \mathrm{degC}, 5$ times performed ※HAST: $100 \mathrm{hr}$

※surface roughness was measured by WYKO after $\mathrm{Cu}$ etching.

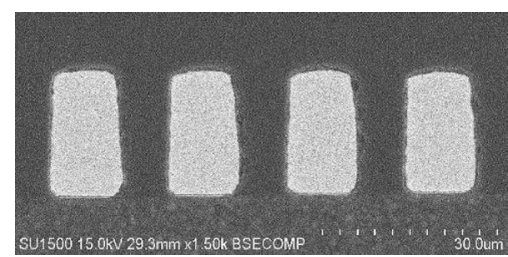

Fig. 4 Cross sectional SEM of line and space with $12 / 12 \mu \mathrm{m}$.

\subsection{Fine line formation}

As mentioned above, circuit boards having very fine line formation of less than $\mathrm{L} / \mathrm{S}=15 / 15 \mu \mathrm{m}$ are strongly desired for high performance electronic devices. Therefore, the lithographic process of semi-additive process was applied to create a comb pattern of $12 / 12 \mu \mathrm{m}$ using an ABF-RCC sample which was prepared with the described method (2.2). The cross sectional SEM of fine line patterning is shown in Figure 4. The fine line patterning was easily formed owing to the smooth interface.

\section{Core Material, Copper Clad Laminates (CCL) Consisting of ABF-Glass Cloth (GC) and Thin Copper Transfer Film/AGL-1020}

\subsection{Construction and characteristics}

Figure 5 shows the construction of AGL-1020, which consists of thin copper transfer films and prepregs. The resin composition of prepreg is similar to that of $\mathrm{ABF}$ and has the specific feature of high adhesion to smooth copper. Table 3 shows the general characteristics of AGL-1020 (0.2 $\mathrm{mm}$ thick).

\subsection{Adhesive strength and reliabilities}

The adhesive strength and reliabilities were evaluated by the following process: First, two sheets of prepreg were placed between two thin copper transfer films and pressed

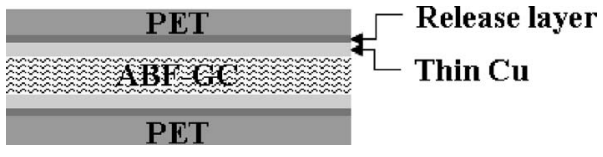

Fig. 5 Construction of AGL-1020.

Table 3 General characteristics of AGL-1020

\begin{tabular}{c|c|c}
\hline Test condition & Unit & AGL-1020 \\
\hline $\begin{array}{c}\text { CTE x-y (25-150 degC) } \\
\text { (tensile TMA) }\end{array}$ & $\mathrm{ppm} / \mathrm{degC}$ & 13 \\
\hline $\begin{array}{c}\text { CTE x-y (150-240 degC) } \\
\text { (tensile TMA) }\end{array}$ & $\mathrm{ppm} / \mathrm{degC}$ & 8 \\
\hline Tg (tensile TMA) & $\operatorname{degC}$ & 180 \\
\hline Tg (DMA) & $\operatorname{degC}$ & 190 \\
\hline $\begin{array}{c}\text { Dielectric constant } \\
\text { (Cavity perturbation, 5.8 GHz) }\end{array}$ & - & 4.5 \\
\hline $\begin{array}{c}\text { Loss tangent } \\
\text { (Cavity perturbation, 5.8 GHz) }\end{array}$ & - & 0.017 \\
\hline Flame retardancy (UL94) & - & $\doteqdot \mathrm{V} 0$ \\
\hline
\end{tabular}

Table 4 Results of peel strength and reliability tests for AGL-1020

\begin{tabular}{c|c|c}
\hline Tests & Unit & Results \\
\hline $\begin{array}{c}\text { Peel strength } \\
\text { (initial) }\end{array}$ & $\mathrm{kgf} / \mathrm{cm}$ & 0.73 \\
\hline $\begin{array}{c}\text { Peel strength } \\
\text { (after HAST and precondition) }\end{array}$ & $\mathrm{kgf} / \mathrm{cm}$ & 0.8 \\
\hline $\begin{array}{c}\text { Reflow tests } \\
\text { (after HAST and precondition) }\end{array}$ & - & No blister \\
\hline Surface roughness & $\mathrm{nm}$ & $\begin{array}{c}\text { Ra: } 50 \\
\text { Rz: } 900\end{array}$ \\
\hline
\end{tabular}

※Precondition: JEDEC Level 2

※Reflow max temp.: $262 \mathrm{degC}, 5$ times performed ※HAST: $100 \mathrm{hr}$

※surface roughness was measured by WYKO after $\mathrm{Cu}$ etching.

in a vacuum hot press machine. The conditions in the vacuum hot press were $30 \mathrm{~min}$ at $130 \mathrm{degC}$ and $1 \mathrm{MPa}$, and a further $90 \mathrm{~min}$ at $190 \mathrm{degC}$ and $3 \mathrm{MPa}$. After removal of the PET film and release layer using the same method as in Section 2.3, a $0.3 \mu \mathrm{m}$ electroless copper plating layer was formed on the thin copper layer. After that, the sample was dried at $80 \mathrm{degC}$ for $15 \mathrm{~min}$. Next, a $25 \mu$ m electrolytic copper-plating layer was formed on the electroless copper plating layer. After electrolytic copper plating, the sample was annealed at $180 \mathrm{degC}$ for $30 \mathrm{~min}$. The annealed sample was used for the tests of adhesion strength and reliability. 
The conditions of the reliability tests are the same as those described in Section 2.4.

As can be seen in Table 4, the developed material, AGL1020, has a high adhesion strength with ultimately low roughness. Reliability tests showed the robust interface between ABF-GC and smooth copper, which seems promising for future fine-line core boards.

\section{Discussion}

The developed RCC and CCL using thin copper transfer films provide high peel strength without anchor effects. The mechanism of these phenomena is deduced by XPS analysis of the interface. The specific functional groups, for example ester, hydroxyl, ether, and aromatic rings in the resin composition, coordinate to the copper deposited by

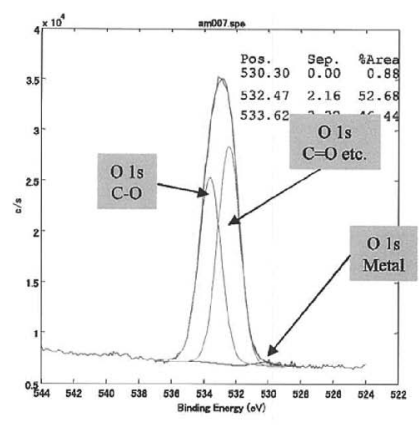

Cured without thin copper

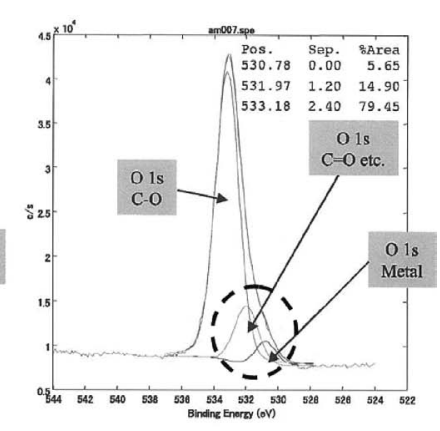

Cured with thin copper
Fig. 6 Narrow spectrum of Oxygen by XPS on resin surface of $\mathrm{ABF}-\mathrm{RCC}$ after $\mathrm{Cu}$ etching.

Table 5 Ratio of the different kinds of O-bond

\begin{tabular}{c|c|c|c|c}
\hline Condition & Unit & C-O & C=O etc & O-Metal \\
\hline Cure without thin copper & \multirow{2}{*}{ atomic $\%$} & 46.44 & 52.68 & 0.88 \\
\cline { 3 - 5 } Cure with thin copper & & 79.45 & 14.90 & 5.65 \\
\hline
\end{tabular}

vacuum evaporation or sputtering to form oxygen-copper bonds. Thus, the self-assembly interaction between copper and chemical groups, including oxygen, in the resin composition leads the high adhesion without anchor effects. The XPS analysis shown in Figure 6 and Table 5 supports that assumption. The resin surface after copper etching of RCC or AGL-1020 was analyzed and compared with the resin surface cured without thin copper transfer films. Some specific bonds on the surface cured with thin copper were observed more than that cured without copper.

\section{Conclusion}

By combining the copper transfer film with a new $\mathrm{ABF}$ which has a very low CTE, a high Young's modulus, and a low dielectric loss tangent, we developed an ABF-RCC for build-up dielectric material which can produce high adhesion with ultimately low roughness. Furthermore, a CCL which can make very fine patterns from the core material was developed by using a thin copper transfer film and ABF-GC. Both developments are suitable for making fineline PCBs, including substrates of CSP and BGA, for further miniaturizing electric devices. We would like to promote such developments to contribute to the progress of electronics in society.

\section{References}

[1] K. Takagi, "Technologies of build-up multi-layer printed circuits boards," Nikkan Kougyo Shimbun, Ltd., 2000.

[2] G. Mago, "Interlayer insulating film for printed circuit boards," Electric material, Vol. 44, pp. 57-60, 2005.

[3] S. Hashimoto, J. Noda, and K. Hattori, JP2002-324969, 2002. 